\title{
NOTAS SOBRE OS TERRITÓRIOS NA ANÁLISE GEOECONÔMICA
}

\author{
NOTES ON THE TERRITORIES IN GEO-ECONOMICS ANALYSIS
}

\author{
Jandir Ferrera de Lima ${ }^{1}$ \\ Recebido em 10/09/2011 \\ Aceito em 29/11/2011
}

\begin{abstract}
RESUMO
O objetivo deste artigo é examinar a emergência dos territórios na perspectiva da análise econômica espacial. A concepção do território, como elemento privilegiado de análise, tem suas origens em alguns acontecimentos ou fatos mais gerais, que são: as transformações na teoria econômica espacial, as transformações nas atividades de produção e as transformações na economia mundial. No entanto, falta ainda uma compreensão de como o capital se reproduz e se transforma nos territórios. Em alguns casos, mais do que crescimento e lucro, a motivação dos empresários origina-se de outros fatores internos das comunidades, como a solidariedade e fatores culturais.
\end{abstract}

Palavras-chave: Territórios. Desenvolvimento regional. Economia espacial. Geoeconomia. Economia regional.

\begin{abstract}
The aim of this paper is to analyze the emergence of territories according the perspective of space economic analysis. The conception of territory as a privileged element of analysis has its origins in some events or facts such as: the transformations in the space economic theory, the transformations in the production activities and the transformations in the world economy. However, there is not yet an understanding of how capital reproduces and transforms itself in the territories. In some cases, more than growth and profits, the motivation of entrepreneurs originates in other internal factors of the communities, for example solidarity and cultural factors.
\end{abstract}

Keywords: Territories. Regional development. Space economy. Geo-economy. Regional economy.

\footnotetext{
Ph.D. Desenvolvimento Regional (UQAC/Canadá). Professor do Programa de Pós-Graduação em Desenvolvimento Regional e Agronegócio da Universidade Estadual do Oeste do Paraná (UNIOESTE), Campus de Toledo, PR. Pesquisador e bolsista do Conselho Nacional de Desenvolvimento Científico e Tecnológico (CNPq). Pesquisador associado do CRDT (Canadá), do GEPEC/UNIOESTE e da Fundação Araucária. E-mail: <jandir.lima@unioeste.br; jandirbr@yahoo.ca>
} 


\section{Introdução}

Atualmente, é consenso nas ciências humanas e sociais que o espaço representa mais que um simples quadro de localização dos agentes econômicos. Segundo Pecqueur (1996), o espaço representa a emergência e a representatividade de um "ator" econômico, cuja importância ganhou um lugar especial nos estudos sobre as regiões. Esse "ator" é o território, que surge como um resultado, uma síntese do local e do mundial, da estruturação organizacional das empresas e instituições.

Assim, a emergência do território na nova análise geoeconômica, durante o século $\mathrm{XX}$, é o resultado de três configurações: os distritos industriais, os sistemas produtivos locais e redes de inovações (BENKO, 2001; FORTIN, 2002; CHIASSON, 2004). Mas estas configurações têm suas origens em alguns acontecimentos ou fatos mais gerais, quais sejam: as transformações na teoria econômica espacial, as transformações nas atividades de produção e as transformações na economia mundial.

$\mathrm{Na}$ economia, as transformações mundiais e os conflitos de produção e de distribuição provocaram uma modificação na interpretação da realidade econômica e das organizações. Com a grande crise de 1929, e a necessidade de soluções a curto-prazo para o desemprego, a inflação e a recessão, ganharam mais espaço nas preocupações dos pesquisadores econômicos. A busca de soluções para estas questões conduziu a novos conceitos, a diferentes formas de interpretação dos fenômenos. No ambiente das ciências sociais, principalmente da economia, nasce a necessidade da interdisciplinariedade. Esta necessidade introduz novos conceitos e formas de análise na economia, sociologia e na geografia e conduzirá à formação da ciência regional. Esse artigo fornece elementos para a compreensão da emergência dos territórios na análise econômica espacial.

\section{A teoria econômica tradicional e a noção de espaço econômico e territórios.}

Os problemas de estagnação e de desequilíbrios macroeconômicos surgidos depois de 1960 ressuscitaram o pensamento neoclássico, em desuso após a revolução keynesiana de 1930. Esta situação demonstra a dificuldade do pensamento econômico em renovar seus conceitos e a explicar os fenômenos ligados à produção e ao movimento dos territórios. Esta incapacidade resulta de modelos fechados, sem relações dinâmicas e que consideram o espaço como neutro, que marcam as construções teóricas da ciência econômica. Assim, segundo Lacour (1996), é preciso explicar o ordenamento dos agentes econômicos, dos fatores de produção, dos espaços, das regiões, das instituições, pois demandam análises que vão além da concepção walrasiana do mundo econômico. Há uma necessidade patente na análise econômica de entender as regularidades, as questões qualitativas e estruturais do desenvolvimento econômico e promover os princípios da regulação e orientação da política econômica.

No entanto, quando se insere a concepção do espaço e dos territórios, como elementos dinâmicos e de análise no escopo da economia, deve-se considerar a cultura, a política, a história, a tecnologia e os sentimentos de parceria e orgulho dos povos como questões importantes nos estudos das regiões e de seu desenvolvimento. Essas questões têm um impacto direto face à irrealidade das teorias econômicas conservadoras, principalmente daquelas que trabalham com a hipótese de um mundo perfeito, mecânico, avesso aos riscos e incertezas, sob uma ordem natural, que caracteriza a análise de algumas escolas do pensamento econômico. De um mundo fechado, a concepção de espaço e território exige novas dimensões de análise, que estão além da teoria econômica tradicional.

Para a economia neoclássica, por exemplo, o mercado se ajusta em seu ponto de equilíbrio e os agentes econômicos, sem intervenções exógenas, farão as melhores escolhas para a alocação ótima dos recursos. É um universo perfeito em que as externalidades negativas serão corrigidas pelo sistema de preços e o principal objetivo é a maximação da utilidade. Para os neoclássicos, nesse modo de pensar a economia, as regiões formam pequenos mercados, que buscam seu equilíbrio. Quando o conjunto desses pequenos mercados encontra seu equilíbrio, então toda a economia se ajusta.

$\mathrm{Na}$ teoria econômica tradicional o espaço em si não existe, os consumidores não se movimentam, as atividades localizam-se em um único ponto. As regiões e o espaço econômico não têm uma dinâmica própria. Elas são apenas a extensão de um grande mercado, sem influência e representatividade. 
Até mesmo a ideia dos distritos industriais perde seu valor, porque as aglomerações são elementos passivos ao equilíbrio de mercado a longo prazo. Assim, os efeitos externos devem ser sempre positivos para formar situações suficientes de equilíbrio. (PECQUEUR; COURLET, 2001).

Essas ideias representam um mundo estável, com as mesmas características, sem distinções físicas, políticas e territoriais. Esta concepção é compreensível, no ambiente de uma teoria estática, porque a ideia de territórios dinâmicos, com a possibilidade de um movimento diferente dos interesses de uma unidade central, onde o equilíbrio de mercado é totalmente dependente do seu movimento, torna impossível a existência de uma economia perfeita. Esta realidade pode ser ilustrada com um exercício teórico do próprio pensamento neoclássico

Suponham-se funções interdependentes de utilidade, em que há dois territórios $\left(U_{1}, U_{2}\right)$, que têm funções expressas pelas equações (1) e (2):

$$
\begin{aligned}
& U_{1}=U_{1}\left(q_{11}, q_{12}, q_{21}, q_{22}\right) \\
& U_{2}=U_{2}\left(q_{11}, q_{12}, q_{21}, q_{22}\right)
\end{aligned}
$$

Então, $\mathrm{q}_{1}$ e $\mathrm{q}_{2}$ refletem a quantidade (q) dos recursos utilizados ( 1 e 2) na estrutura de produção dos

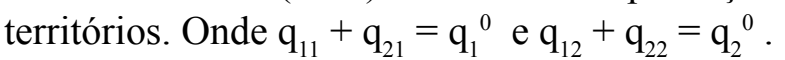

Assim, a maximização da utilidade do território $\mathrm{U}_{1}$ está sujeita a restrição de utilidade da região $\mathrm{U}_{2}$, depois que ela se conserva constante $\left(\mathrm{U}_{2}{ }^{\#}\right)$. Tem-se:

$$
\begin{aligned}
& U_{1}^{*}=U_{1}\left(q_{11}, q_{12}, q_{1}^{0},-q_{11}, q_{20}-q_{12}\right)+\lambda\left[U _ { 2 } \left(q_{11},\right.\right. \\
& \left.q_{12}, q_{10}-q_{11}, q_{20}-q_{12}\right)-U_{2}^{\#]}
\end{aligned}
$$

Nas condições de primeira ordem:

$$
\begin{aligned}
& \partial U_{1}^{*} / \partial q_{11}=\partial U_{1} / \partial q_{11}-\partial U_{1} / \partial q_{21}+\lambda\left[\partial U_{2} / \partial q_{11}-\partial U_{2} / \partial q_{21}\right]=0 \\
& \partial U_{1}^{*} / \partial q_{12}=\partial U_{1} / \partial q_{12}-\partial U_{1} / \partial q_{22}+\lambda\left[\partial U_{2} / \partial q_{12}-\partial U_{2} / \partial q_{22}\right]=0 \\
& \partial U_{1}^{*} / \partial \lambda=U_{2}\left(q_{11}, q_{12}, q_{10}-q_{11}, q_{2}^{0}-q_{12}\right)-U_{2}^{\#}=0
\end{aligned}
$$

Tem-se então:

$$
\frac{\partial U_{1} / \partial q_{11}-\partial U_{1} / \partial q_{21}}{-\partial U_{1} / \partial q_{12}-\partial U_{1} / \partial q_{22}}=\frac{\partial U_{2} / \partial q_{11}-\partial U_{2} / \partial q_{21}}{\partial U_{2} / \partial q_{12}-\partial U_{2} / \partial q_{22}}
$$

Estas são as condições necessárias para estabelecer um "ótimo de Pareto", com funções interdependentes de utilidade.

A posição das derivadas indica que o nível de demanda ótimo de um território é dependente do nível do outro. Como consequência, o nível de utilização que um território ou região faz dos recursos escassos (e até mesmo a polarização do crescimento) irá influenciar na dinâmica e no uso desses recursos de outro território ou região. Assim, o distrito industrial do território $\mathrm{U}_{1}$ torna-se dependente do território $\mathrm{U}_{2}$ na forma de utilizar os seus próprios recursos.

Historicamente, essa situação hipotética comporta o abandono da ideia da concorrência perfeita e estimula a criação de outras interpretações sobre o funcionamento das estruturas de mercado, principalmente por Joan Robinson e Edwards Chamberlain. Conforme Pecqueur (1996), essas ideias dão à análise econômica espacial a concepção da diferenciação de produtos, da interação entre os agentes heterogêneos e da possibilidade de economias de escala com diferentes dinâmicas. Estes elementos vão inspirar as teorias do desenvolvimento econômico desequilibrado e até mesmo a ideia de um crescimento que surge concentrado. A "teoria dos polos" de crescimento econômico, de Perroux (1955), marca uma nova forma de pensar o processo de desenvolvimento econômico e insere as regiões no contexto de discussão da teoria econômica contemporânea.

A "teoria dos polos" crê no contexto do desenvolvimento econômico desequilibrado. Ela surge como uma reação à ideia do equilíbrio no processo de crescimento da economia, ao contrário do pensamento marshalliano. Isso é consequência da influência do pensamento de Joseph Schumpeter e das críticas à concepção do processo de crescimento equilibrado. Assim, a visão do desenvolvimento econômico se reforma, como um processo que propaga através de impulsos sem equilíbrio entre as unidades produtivas, as regiões e os territórios.

Neste ambiente, as ideias de François Perroux encontram um campo fértil para as proposições teóricas, com muitos elementos que são próximos às ideias da dinâmica do desenvolvimento econômico propostas por Hirschmann (1961), que analisa a situação dos países subdesenvolvidos. Mas em Perroux (1955, 1962, 1967), a preocupação central é a realidade e polarização nos países capitalistas desenvolvidos. 
Perroux (1982) analisa o espaço econômico a partir de dois prismas. Primeiro: examinando e descrevendo o relacionamento e a distribuição das atividades econômicas no espaço geográfico. Essas atividades localizam-se através de suas coordenadas ou mapeamento. Segundo: o espaço econômico corresponde a relações conceituais mais amplas. Por exemplo, uma empresa ou indústria, ou um grupo delas, pode localizar sua produção em uma determinada área, porém seu mercado de insumos ou de produto pode estar localizado dentro ou não do mesmo espaço geográfico.

Com isso, o espaço polarizado corresponde a um campo de forças ou de relações funcionais. Ele corresponde às interdependências ou intercâmbios entre os espaços homogêneos, ou seja, consistem em centros (polos ou nó) dos quais emanam forças centrípetas (de atração) e centrífugas (de repulsão). Cada centro atuando forma um campo de atuação próprio. Então, espaço ou região polarizada é o lugar em que há intercâmbio de bens e serviços, do qual a intensidade de intercâmbio interior é superior, em cada um de seus pontos definidos, à intensidade exterior.

Por outro lado, o que caracteriza se o espaço polarizado é de crescimento ou desenvolvimento depende da sua capacidade de produzir transformações estruturais nas regiões. Por exemplo, os polos de desenvolvimento que conduzem a modificações estruturais e que abrangem toda a população da região polarizada. O polo de crescimento, mesmo motivando o crescimento do produto e da renda, não provoca transformações significativas das estruturas regionais.

Para Jean (1998), como o polo de crescimento não transforma as estruturas regionais, a ideia do desenvolvimento regional emerge de uma nova concepção teórica, política e de gestão dos territórios. É a emergência de uma nova abordagem do desenvolvimento "da base em direção ao alto", de uma visão particular versus uma visão homogeneizante que caracteriza o pensamento neoclássico, keynesiano e marxista. A ideia do desenvolvimento econômico surge como endógeno, descentralizado, local e que tem nos territórios um elemento novo de análise.

Mas, não é somente a teoria que muda. Na realidade, a teoria busca explicar o real. Ela deve acompanhar as transformações da sociedade moderna. A emergência dos territórios é acompanhada de transformações nas atividades produtivas. Essas transformações são um elemento importante para compreender o desenvolvimento regional.

\section{As Atividades de Produção e os Territórios}

Quanto às transformações nas atividades de produção, pode-se citar o papel da pesquisa e do desenvolvimento (P\&D), o empresariado, os grupos locais, os efeitos dos recursos materiais (ambiente inovador), as diferentes dotações de recursos naturais de um espaço a outro. Estas transformações mudam a dinâmica dos territórios, das regiões e formam a tectônica que produz interdependências, concorrências, complementaridades, diversas possibilidades de exploração econômica e de transformações sociais (PROULX, 2001).

Com a criação de pequenas empresas, com as intervenções políticas das associações empresariais, com o surgimento de novas tecnologias para a exploração dos recursos, que surgem com a pesquisa, demonstra-se que há uma relação entre o território, as empresas e o desenvolvimento econômico (JULIEN, 1994).

$\mathrm{Na}$ realidade, a presença de grupos políticos fortes e os interesses do capital industrial fazem surgir novos locais próprios para os investimentos e que chegam ao status de uma região ou distrito industrial. Além disso, há capacidade de empreendedorismo dos ambientes inovadores, as redes de informação e as próprias inovações que dão uma nova perspectiva ao progresso local. A capacidade de empreender tem diferentes mensurações, mas exerce um papel cada vez maior na formação das economias locais e também na importância socioeconômica das regiões e dos territórios.

Então, a ideia de um "desenvolvimento pelo alto" dá lugar a uma perspectiva de "desenvolvimento pela base". Para Proulx (1994), é preciso notar que o desenvolvimento pelo alto foi muito encorajado pelo novo fato do empresariado ter deduzido que as atividades que criam empregos são agora as pequenas e médias empresas, e não mais as grandes. Isto é uma transformação na forma de pensar o espaço, agora com uma autonomia própria de desenvolvimento e de crescimento econômico, principalmente porque as grandes empresas não são as únicas responsáveis pela dinâmica das regiões. 
Assim, nasce a perspectiva de um novo paradigma que tem necessidade de novos conceitos, porque nas teorias tradicionais a força da dinâmica econômica é produzida por elementos exógenos, mas com perspectivas locais, esses elementos são endógenos (GASSE, 1994). Esta perspectiva dá base para uma nova teorização que tem na concepção de território um elemento importante. Segundo Boisvert (1998), na concepção de território há outras questões que podem influir diretamente no consumo e na produção dos bens, como o sentimento de fazer parte de uma coletividade ou ainda os mecanismos de aprendizagem e de consciência coletiva.

Estes novos elementos (e questões) exigem outra forma de análise dos fenômenos econômicos, humanos e alguns princípios da geografia, como a teoria dos lugares centrais. A importância das regiões, dos territórios e da economia local pode ser dada por muitos fatores endógenos e não somente pela localização de seus recursos. Há alguns fatores que podem explicar as características territoriais e não são puramente econômicos. Na opinião de Lacour (1996), os territórios servem de intermediação, de revelação, de concretização aos comportamentos dos agentes. Esta intermediação ligará local e mundial, as técnicas e as resistências.

A construção do espaço sobre critérios físicos como a distância, a centralização, a concentração e a interação deve mudar para poder englobar questões imateriais, como a cultura, as tradições, o processo histórico. Os homens produzem um espaço que é carregado dessas características, sua cultura e significação, que fazem a emergência do território, o que caracteriza a transformação no determinismo de algumas ciências por um "possibilismo" ou possibilidades humanistas (PROULX, 1998; JEAN, 1998).

A noção de espaço tem um lugar importante na construção do mundo moderno. Sobre o espaço geográfico das regiões são produzidos os bens de subsistência, os excedentes para as trocas, assim como mudanças científicas, culturais, políticas, biológicas, geográficas e econômicas. Por isso, sobre o espaço há várias relações entre os objetos e as ações. Para Santos (1997), os objetos e as ações são os elementos principais na definição de espaço. Com eles é possível analisar suas categorias internas que são a paisagem, os territórios e os relevos. A paisagem é um conjunto de formas e ela exprime a ação do homem.
O território é um conjunto de elementos naturais e artificiais que caracterizam um espaço em particular. Os relevos são formas da paisagem e a matéria sobre a qual se produzem as ações humanas.

Estas categorias ganham diferentes interpretações, porque o espaço geográfico é uma imagem, um reflexo do desenvolvimento de um grupo social num período da história. O espaço geográfico é um elemento, um produto da acumulação do capital e da reprodução social. Por isso, a concepção de espaço se intercala entre os diversos conceitos da geografia, da economia e da sociologia. O espaço não é um elemento isolado, mas interdependente, o que pode ser observado no âmbito das regiões. Bailly (1983) propõe o conceito de espaço como um território em que os grupos (e as ideologias) agem e impõem seus objetivos e suas práticas. $\mathrm{O}$ território, em um momento preciso, é um território onde se fazem a concentração, o estabelecimento, a dispersão humana e a localização das atividades produtivas dos indivíduos.

Estas possibilidades vão necessitar de novos modelos de desenvolvimento em que os blocos territoriais têm um lugar privilegiado, para combinar a relações profissionais (capital/trabalho) e a organização industrial (inter-firmas). Segundo Lipietz e Leborgne (1992), os territórios vão se impor hegemonicamente, num conjunto de comportamentos culturais, sociais, esquemas mentais, que se condensam em compromissos institucionais no âmbito nacional e regional. Desta trajetória nascem as redes de informação, os sistemas industriais locais, as hierarquias urbanas, e ela reforça a necessidade de uma concepção do território na geoeconomia. Mas, estes fatos e situações se apoiam também nas transformações da economia mundial. Segundo Lacour (1996), são os mecanismos da mundialização que reinventam o local e com ele o território. O território nasce dos conflitos da dialética entre o local e o global.

\section{A Economia Mundial e a Concepção dos Territórios.}

Com o crescimento ocorrido no pós-guerra, há uma nova tendência à estruturação do espaço, porque a acumulação do capital busca novas fronteiras, novos mercados e novas necessidades para sua reprodução. Assim, a necessidade de produção e de consumo prende as regiões e territórios em uma realidade 
global. Cada território e cada região têm uma história e uma biodiversidade, que são incontornáveis para a estrutura de produção. Então, a nova visão do desenvolvimento regional deve preocupar-se mais com a realização das potencialidades de cada região do que com a forma de inseri-la na polarização dos grandes centros de transformação.

Segundo Claval (1995), isto representa a passagem de uma visão negativa das disparidades regionais para uma visão das possibilidades da diversidade. Este contexto marca o nascimento de programas governamentais para mudar a situação das disparidades e das diversidades. Nascem, então, novas interpretações sobre as formas de regulação do sistema produtivo locais, que é necessário para analisar a dinâmica das regiões e dos territórios no interior da economia mundial. Para esta análise, o pensamento tradicional, principalmente o ligado à teoria dos lugares centrais e das redes de informação, não é suficiente. Com a economia mundial, os territórios e as economias locais são sujeitas a uma transformação global que produzem os corredores de desenvolvimento. Para Tellier (1998), eles são o produto da história e da geografia. Os corredores representam a geografia do poder econômico e até mesmo da polarização no espaço. Mesmo assim, há os territórios periféricos, que estão fora dos corredores e têm uma dinâmica diferenciada. Estes espaços, geralmente, têm uma estrutura empresarial bem estruturada, empresários inovadores, bacias de recursos e um bom nível de investimentos em educação. Eles não retêm a mão de obra qualificada. Seus capitais e suas empresas tendem a se integrar na economia dominante e não a se isolar.

Então, o nascimento dos territórios, na nova geoeconomia, tem uma parte de sua concepção ligada aos movimentos do mercado global. As teorias convencionais do desenvolvimento regional dão ao crescimento ligado à base de exportação um papel importante. Mas, os espaços impõem uma dinâmica que os torna um componente do crescimento mundial. Nesse crescimento, a base de exportação surge mais como um movimento natural dos territórios, do que como o elo mais importante de sua dinâmica espacial.

No entanto, esta internacionalização dos territórios e dos espaços regionais, dinamizados por vantagens comparativas localizadas, estimulam aptidões e a competitividade local. Esta competitividade aumenta com a produtividade e as mudanças cambiais que favorecem algumas nações.

Assim, os distritos industriais, os ambientes de inovação e os sistemas produtivos locais dão um suporte especial à acumulação do capital, principalmente quando eles não estão próximos dos grandes centros, mas em áreas periféricas e que têm territórios ou regiões emergentes ou em transição.

\section{Conclusão}

Os fatos estão sempre além das teorias. Isto ocorre porque o objetivo da teoria é explicar a realidade. Assim, a dinâmica dos fatos deve estar bem clara para que a ciência possa observar e produzir os conhecimentos sobre os fatos.

Isto também se produz com os territórios e com as regiões. Como a economia é global, com os mesmos tipos de mercadorias no globo, o mesmo sistema econômico hegemônico de produção, mas sob diferentes formas, como as redes de informação se organizam, o empresariado faz a gestão e as instituições exercem sua influencia nos espaços.

Assim, na economia contemporânea, as economias regionais correspondem a uma realidade do capital. Com a ação dos grupos locais, há dinâmica econômica. Mas esta dinâmica deve acompanhar as tendências da economia mundial.

Os distritos industriais, os ambientes de inovação e os sistemas produtivos locais estão sob uma base de produção que se transforma, mas sempre com o mesmo objetivo: o lucro e o crescimento. As possibilidades de atingir estes objetivos ocorrem de acordo com os recursos e as possibilidades disponíveis. Esta é uma realidade de todos os territórios e regiões, mas as grandes questões são a criação de possibilidades e os caminhos para o crescimento. Estas possibilidades são variáveis e mudam segundo os novos modelos de acumulação e dos centros de decisão. Os postulados dos distritos industriais, dos ambientes de inovação, dos corredores de desenvolvimento e dos sistemas produtivos locais dão uma nova interpretação à questão do desenvolvimento regional e do papel dos territórios.

$\mathrm{Na}$ realidade, os territórios constituem uma nova forma de analisar os problemas do desenvolvimento econômico e da eficiência das 
atividades produtivas. Mas mesmo os territórios que compõem o sistema produtivo mundial se organizam sobre uma base de exportação. Então, mesmo com características próprias, sua estrutura de produção deve se integrar ao dinamismo do capital nas regiões, nos países e em todos os espaços. Sob este prisma, pode-se afirmar que todos os territórios e as mudanças na análise espacial regional correspondem à realidade. Mas a dinâmica dos territórios tem necessidade de uma nova teorização que envolva o espírito empreendedor e a ideia de desenvolvimento local. Essa nova teorização se impõe porque o papel e a ligação dos territórios na dinâmica do capital ainda são obscuros. Assim, esta questão é importante na compreensão da nova geoeconomia.

Atualmente, as transformações na economia mundial, na teoria econômica e nos sistemas produtivos locais, dão um sistema de informações sobre as dinâmicas territoriais que serão úteis à ciência regional. Além disso, a emergência dos territórios é um produto dessas transformações. Mas, para ser possível uma análise coerente, a nova geoeconomia deve incorporar uma análise do capital no espaço.

Falta ainda uma compreensão de como o capital se reproduz e se transforma nos territórios, porque, em alguns casos, mais do que crescimento e lucro, a motivação dos empresários se deve a outros fatores internos das comunidades, como a solidariedade e fatores culturais.

Portanto, a emergência dos territórios faz parte do movimento do capital. Assim, a nova geoeconomia deve buscar descobrir a dinâmica espacial do capital nos territórios, com novas teorias, novos conceitos e postulados, para poder encontrar elementos condizentes para a explicação do desenvolvimento regional.

\section{REFERÊNCIAS}

BAILLY, A. S. Espace géographique et espace vécu. In: PAELINCK, J.; SALLEZI, A. (Org.). Espace et localisation. Paris: Éditions Economica, 1983. p. 290-303

BENKO, G. Economia, espaço e globalização na aurora do século XXI. 2.ed. São Paulo: Hucitec, 2001.

BENKO, G.; LIPIETZ, A. (Org.). Les régions qui gagnent. Paris: PUF, 1992.

BOISVERT, M. L'Analyse économique régional : Éventail de concepts, anciens et nouveaux. PROULX, M-U (Org.) Le phénomène régional au Québec. Québec: Presses Universitaires de 1'Université du Québec, p.187-211, 1998.
CLAVAL, P. Comment s'organise l'espace régional? Revue Sciences Humaines. Hors-série, $\mathrm{n}^{\mathrm{o}}$ 8, février-mars, p.6-8, 1995.

CHIASSON, G. L 'attractivité des territoires dans un contexte de mundialisation: quel espoir pour les millieux ruraux de l'Outaouais? Organisations et Territoires. Québec, v.13, n.1, p.77-82, 2004.

CREVOISIER, O. Mondialisation et territorialisation de l'économie : les approches homogénéisante et particularisant. In: PROULX, M-U. (Org.). Territoires et développement économique. Montréal: Éditions L'Harmattan, 1998. p. 2348.

LACOUR, C. La tectonique des territoires: d'une métaphore à une théorisation. PEQUEUR, B. (Org.). Dynamique territoriale et mutations économiques. Montréal: L'harmattan, 1996. p. 25-48.

FORTIN, A. Territoires de l'identité, territoires de la culture. Organisations et Territoires. Québec, v.11, n. 01, p.39-42, 2002.

GASSE, Y. L'appropriation de développement économique local par l'entrepreneuship : Le cas du Québec. In : PROULX, M-U. (Org.). Développement économique: la clé de l'autonomie local. Québec : Éditions transcontinentales, 1994. p.45-74.

HIRSCHMANN, A. Estratégia del desarrollo económico. México: FCE, 1961.

JEAN, B. Les régions sur le regard sociologique : la construction sociale du fait régional. In: PROULX, M-U. (Org.). Le phénomène régional au Québec. Québec: Presses Universitaires de l'Université du Québec, 1998. p.133-156.

JULIEN, P. A. Entrepreneuriat, développement régional et appropriation de l' information. In: PROULX, M-U (Org.). Le phénomène régional au Québec. Québec: Presses Universitaires de 1'Université du Québec, 1994. p.215-241.

LIPIETZ, A.; LEBORGNE, D. Flexibilité offensive et flexibilité défensive: deux stratégies sociales dans la production des nouveaux espaces économiques. In: $\mathrm{BENKO}, \mathrm{G}$.; LIPIETZ, A. (Org.). Les régions qui gagnent. Paris: PUF, 1992, p.347-378.

PAELINCK, J.; SALLEZI, A. (Org.). Espace et localisation. Paris: Éditions Economica, 1983.

PECQUEUR, B. (Org.). Dynamique territoriale et mutations économiques. Montréal: L'Harmattan, 1996.

; COURLET, C. Développement économique et territoire : quels rapports? In: COLLOQUE DE L'ASSOCIATION DE SCIENCE RÉGIONALE DE LANGUE FRANÇAISE, 37. Actas... Bordeaux: Université Montesquieu-Bordeaux IV, 2001. 
.; __ Systèmes productifs localisés et développement : Le cas des économies émergentes et en transition. PROULX, M-U. (Org.). Territoires et développement économique. Montréal: Éditions L'Harmattan, 1998. p.49-66.

PERROUX, F. Dialogue des monopoles et des nations : équilibre ou dynamique des unités actives? Grenoble: Presses Universitaires de Grenoble, 1982.

. A economia do Século XX. Lisboa : Herber, 1967.

Le capitalisme. Paris: Presse Universitaire de France, 1962.

. Notes sur a conception des pôles de la croissance . Économie Appliquée, n.1-2, 1955. p. 309-320.

PROULX, M-U. La tectonique des territoires québécois. Sommaire Executive. Québec : DSEA/Université du Québec à Chicoutimi (UQAC), 2001.

. (Org.). Développement économique : la clé de l'autonomie local. Québec : Éditions transcontinentales, 1994.

(Org.). Le phénomène régional au Québec. Québec : Presses Universitaires de l'Université du Québec, 1998.

SANTOS, M. La nature de l'espace. Paris: L'Harmattan, 1997.

TELLIER, L. N. Le Québec et ses régions à l'intérieur de la dynamique spatiale de l'économie mondiale. Dans PROULX, M-U (org.) Le phénomène régional au Québec. Québec : Presses Universitaires de l'Université du Québec, 1998. p.9-28. 